\title{
28 Research Square \\ Compatibility of Different Commercial Alloys in High Temperature Supercritical Carbon Dioxide
}

Gen Zhang ( $\nabla$ yxyszhang@foxmail.com )

Nuclear Power Institute of China, Chengdu, Sichuan 610213, China.

\section{E Jiang}

Nuclear Power Institute of China, Chengdu, Sichuan 610213, China.

Weiwei Liu

Nuclear Power Institute of China, Chengdu, Sichuan 610213, China.

Hong Yang

Nuclear Power Institute of China, Chengdu, Sichuan 610213, China.

\section{Yulong Wu}

Institute of Surface Science, Helmholtz-Zentrum Hereon, Max-Planck Str. 1, 21502 Geesthacht

Yanping Huang

Nuclear Power Institute of China, Chengdu, Sichuan 610213, China.

\section{Research Article}

Keywords: Supercritical carbon dioxide, Oxidation, Carburization, High temperature

Posted Date: February 14th, 2022

DOI: https://doi.org/10.21203/rs.3.rs-1289505/v1

License: (c) (i) This work is licensed under a Creative Commons Attribution 4.0 International License.

Read Full License 


\section{Abstract}

In this work, compatibility and long-term integrity of candidate structural materials, including austenitic stainless steel $316 \mathrm{NG}$, Fe-Ni based alloy $800 \mathrm{H}$ and Ni-based alloy 625, were tested in high-temperature and high pressure $\mathrm{SCO}_{2}$. The exposure time was up to $3000 \mathrm{~h}$. The results showed that the corrosion kinetics approximately followed a parabolic law for $316 \mathrm{NG}$ and $800 \mathrm{H}$. After $3000 \mathrm{~h}$ exposure, all of oxide layers, mainly composed by $\mathrm{Cr}_{2} \mathrm{O}_{3}$, were continuous, compact and protective, and their thicknesses were about $21 \sim 45 \mathrm{~nm}, 64 \sim 88 \mathrm{~nm}$ and $34 \sim 43 \mathrm{~nm}$ respectively. In case of carburization, dark spots corresponding carbon deposition was observed on the surface and a little enriched in underneath the oxide for $800 \mathrm{H}$. Moreover, enrichment of trace elements was found at oxide/substrate interface through GDOES and TEM analysis, i.e., enrichment of Mn, Si for $316 \mathrm{NG}$, enrichment of $\mathrm{Mn}, \mathrm{Si}, \mathrm{Al}, \mathrm{Ti}$ for $800 \mathrm{H}$ and enrichment of Ti, Al for alloy 625.

\section{Introduction}

Supercritical carbon dioxide $\left(\mathrm{SCO}_{2}\right)$ is being considered as one of the prime coolant candidates for next generation power plants, as it has advantages of higher efficiency, smaller components size, fewer components and simpler cycle layout, etc. [1, 2]. In $\mathrm{SCO}_{2}$ Brayton cycle system, material selection of the key components such as heat exchangers and pipes are one of the important problems of long-term safe operation. In contrast with conventional steam Rankine cycle, the prime consideration in regard to material corrosion is that i) oxidation of some components in higher temperature (RT $\sim 850^{\circ} \mathrm{C}$ ) and higher pressure (0.1 $30 \mathrm{MPa})$ and ii) carburization resulting in material degradation, which is rather unique to $\mathrm{CO}_{2}$ atmosphere.

In the past decades, corrosion data regarding $\mathrm{SCO}_{2}$ are being gradually accumulated and the current investigations focus on the following aspects so far: i) compatibility of structural materials [3-8]. Chen et al. [7] reported corrosion and carburization behaviors of austenitic steels (347H and 316LN) and ferritic/martenitic (F/M) steels (430 and 630) with similar chromium content ( 17.5 wt.\%) and found that spallation of chromia layer occurred for austenitic steels, which was attributed to the lower diffusion coefficients of $\mathrm{Cr}$, larger growth stresses and thermal stresses. Moreover, Olivares et al. [8] compared corrosion resistances of several high-nickel alloys in air and $\mathrm{SCO}_{2}$. Except for low $\mathrm{Cr}$ alloy 282, rates of scaling and internal oxidation were in most cases similar for all alloys in both gases. According to the published studies, it has been known that formation of a continuous chromia $\left(\mathrm{Cr}_{2} \mathrm{O}_{3}\right)$ layer on the substrate materials play a key effect on the corrosion resistance. In addition to conventional commercial alloys, due to better oxidation and carburization resistance of $\mathrm{Al}_{2} \mathrm{O}_{3}$ scales than that of $\mathrm{Cr}_{2} \mathrm{O}_{3}$, alumina forming austenitic (AFA) steels $[9,10]$ was also developed to test in high-temperature $\mathrm{SCO}_{2}$; ii) effect of temperature and pressure [10-13]. As suggested by Mahaffey et al. [10], the weight gain usually increased as testing temperature increase. In contrast, effect of pressure is relatively complicated. Lee et al. [11] suggested that the weight gain and the thickness of an amorphous Clayer at the oxide/matrix interface increased with increasing $\mathrm{CO}_{2}$ pressure from $0.1 \mathrm{MPa}$ to $20 \mathrm{MPa}$. However, for $800 \mathrm{HT}$, the depth 
of the carburized region with Cr-rich carbides was rarely affected by $\mathrm{CO}_{2}$ pressure, resulting in similar tensile properties; iii) effect of impurities in $\mathrm{CO}_{2}$, including $\mathrm{O}_{2}, \mathrm{CO}, \mathrm{H}_{2} \mathrm{O}, \mathrm{H}_{2}, \mathrm{SO}_{2}$ and hydrocarbon [14]. Mahaffey et al. [15] found that oxidation accelerated resulting in formation of a thicker oxide layer and evidence of spallation even with addition $10 \mathrm{ppm} \mathrm{O}_{2}$ for Ni-based alloy 230. Moreover, Oleksaket al.[16] further suggested that $\mathrm{O}_{2}, \mathrm{H}_{2} \mathrm{O}$ and $\mathrm{SO}_{2}$ had negligible effect on the oxidation of ferritic Fe alloys, while $\mathrm{SO}_{2}$ could significantly enhance the rate of oxidation for austenitic Fe alloys; iv) integrity of welding joints, including diffusion-bonded technique [17] toward printed circuit heat exchanger (PCHE) $[1,18]$ and fusion-weld technique [2] and typical gas tungsten arc welding (GTAW)technique [19]; v) preparation of coating on metal substrate, such as deposition of Cu coating [20], Si coating [21], Al coating [22, 23] Cr coating [24,25] and NiAl coating [26];vi) corrosion under stress including static and dynamic stress [27, $28,29]$, including creep and stress corrosion cracking (SCC) so far.

The research progress was simply summarized above. In case of the first aspect, it is the research basic of the others. However, there are also contradictions between different studies. For Example, Chen et al. [7] reported that spallation of chromia layer occurred for austenitic steels, but for F/M steels. However, because thermal expansion is similar between F/M steels and its scales, some researchers found that although a thick oxide layer formed on F/M steels, it's adherence to the substrate was better than that of austenitic steels [28]. Moreover, there are also contrary results on whether amorphous $C$ layer at oxide/substrate interface or Cr-rich carbides in substrate formed. That may because the exposure time used in some experiments was only one thousand hours, even hundreds of hours. And it doesn't seem to further use to correctly predict the corrosion lifetime of the structural materials. This work aims to systematically investigate the corrosion and carburization behaviors of austenitic stainless steel (316NG), Fe-Ni based alloy (800H) and Ni-based alloy (625), including i) corrosion kinetics curve during $3000 \mathrm{~h}$ exposure, ii) surface morphology and composition of the scale using SEM and XRD/Raman analysis, iii) elemental distribution of cross section of the scale using GDOES analysis and iv)elemental enrichment at the oxide/substrate interface, structure, thickness and phase component of the scale using TEM analysis.

\section{Experimental Methods}

\subsection{Materials and specimen preparation}

The alloys used for exposures were acquired from commercial manufacturers and the chemical compositions, detected by the inductively coupled plasma mass spectrometry, were provided in Table 1 . Prior to experiment, the alloys were cut to coupon type specimens following standard JB/T 6074-92 and the detailed dimension was shown as Fig. 1a. The coupon type specimens were then ground on all surfaces up to 2000 grit using SiC papers, followed by drying in warm air. 
Table 1

Chemical compositions of the used commercial alloys (all in wt.\%).

\begin{tabular}{|llllllll|}
\hline Specimens & $\mathrm{Cr}$ & $\mathrm{Ni}$ & $\mathrm{Mn}$ & $\mathrm{Si}$ & $\mathrm{C}$ & $\mathrm{Fe}$ & others \\
\hline $316 \mathrm{NG}$ & 17.34 & 11.79 & 1.42 & 0.42 & 0.025 & Bal. & Mo 2.45 \\
\hline $800 \mathrm{H}$ & 19.70 & 30.63 & 0.90 & 0.25 & 0.06 & Bal. & Al 0.22; Ti 0.35 \\
\hline 625 & 21.46 & Bal. & 0.03 & 0.07 & 0.01 & 2.54 & Mo 8.95; Al 0.36; Ti 0.30 \\
\hline
\end{tabular}

Figure $1 \mathrm{~b}$ shows a schematic of the $\mathrm{SCO}_{2}$ compatibility testing set-up used in this study, comprised by the following five components: (i) $\mathrm{CO}_{2}$ supply system, $\mathrm{CO}_{2}$ cylinders with 99.99\% research grade were used in our study. From the cylinders the $\mathrm{CO}_{2}$ gas traveled through the tubing and flowed into (ii) liquid booster pump, which could increase the pressure to the desired value and bring $\mathrm{CO}_{2}$ to the test section. To make sure the $\mathrm{CO}_{2}$ flowing from the cylinder to the booster pump was liquid state, a water cooler was used to prevent the $\mathrm{CO} 2$ gas from gasifying through the tubing. The liquid $\mathrm{CO}_{2}$ was then heated up to $500{ }^{\circ} \mathrm{C}$ through (iv) pre-heater and became the supercritical fluid. The $\mathrm{SCO}_{2}$ then flowed into (v) the autoclave (test section) which contained the test specimens. The pressure of the autoclave was maintained at $20 \mathrm{MPa}$ by a back pressure regulator (BPR) and the temperature of the autoclave was controlled within $\pm 2{ }^{\circ} \mathrm{C}$ by three zone main heaters. Eventually, the $\mathrm{SCO}_{2}$ flowing from BPR was cooled and its pressure was released. The BPR and the tubing following the BPR were wrapped in Omega lux heating tape, which could prevent $\mathrm{CO}_{2}$ from freezing to plug the pressure-relief vent.

At the beginning of test, twelve duplicate coupons of each alloy were mounted on an alumina sample train and were then put into the autoclave. In this study, the exposing time was up to $3000 \mathrm{~h}$. After $100 \mathrm{~h}$, $200 \mathrm{~h}, 500 \mathrm{~h}, 1000 \mathrm{~h}, 2000 \mathrm{~h}$ and $3000 \mathrm{~h}$ exposure to $\mathrm{SCO}_{2}$, the autoclave was cooled to room temperature and the pressure was decreased to the atmospheric pressure. Subsequently, all of specimens were removed from the autoclave, photo documented and weighed. Two of each alloy was reserved for further analysis, while the other specimens were returned to the autoclave for further testing.

\subsection{Characterization}

After each tests, the weight gain of specimens was measured using a microbalance with a resolution of $0.00001 \mathrm{mg}$. Scanning electron microscopy (SEM; FEI nova 450, USA) equipped with an EDS detector was employed to investigate the surface morphology as well as the chemical compositions of the oxide layers formed during exposure process in $\mathrm{SCO}_{2}$.X-ray diffraction (XRD; Panalytical XPert, Holland) was applied to study the crystal structure and phase composition of the oxide, using a Cu Ka radiation ( $25 \mathrm{kV}$, $40 \mathrm{~mA}$ ) at a glancing angle of $1.5^{\circ}$, in the range of $2 \theta$ from 10 to $80^{\circ}$. Raman spectra were obtained with an argon laser (Renishaw 2000, UK). Depth profile analysis was carried out using glow discharge optical emission spectroscopy (GDOES; GDA750HP, Germany) with an anode of $4 \mathrm{~mm}$ in diameter. A transmission electron microscope (TEM; FEI Themis Z, USA), equipped with a high-angle angular-dark- 
field (HAADF) detector and EDS system, was used at $300 \mathrm{kV}$ for electron diffraction, high-resolution scanning transmission electron microscopy (STEM) imaging and composition analysis. A focused ion beam (FIB; FEI Helios G4 CX, USA) was used to prepare the TEM specimens by the lift-out method.

\section{Results And Discussion}

\subsection{Weight gain and morphology}

The weight gains of $316 \mathrm{NG}, 800 \mathrm{H}$ and 625 alloys during $3000 \mathrm{~h}$ exposure to $\mathrm{SCO}_{2}$ were shown in Fig. 2a. The weight of both $316 \mathrm{NG}$ and $800 \mathrm{H}$ quickly increased at first and continuously increased with exposure time, while that of alloy 625 slightly decreased at first $(<200 \mathrm{~h})$ and then increased, followed by dropping again. It is clearly shown that the corrosion kinetics of $316 \mathrm{NG}$ and $800 \mathrm{H}$ approximately followed a parabolic law, which represented a diffusion-controlled oxide growth rate [30]. The fitting lines based on the formula $\Delta W=K p \sqrt{ } t$ were given in Fig. 2a as well. The lower value of the exponent (0.24 for 316NG and 0.35 for $800 \mathrm{H}$ ) indicated a slow oxide growth kinetic for both. In contrast, the kinetic process of alloy 625 was relatively complicated. Figure $2 b$ shows the oxidation rate at every $1000 \mathrm{~h}$ exposure from each alloy. As for $316 \mathrm{NG}$ and $800 \mathrm{H}$, the oxidation rate significantly decreased with exposure time, which indicated the formed oxide film was protective toward underlying alloy substrate. Although at the initial exposure stage $(0 \sim 1000 \mathrm{~h})$, the oxidation rate of alloy 625 with high $\mathrm{Cr}$ and $\mathrm{Ni}$ content was $1 \sim 2$ order of magnitude lower than that of $316 \mathrm{NG}$ and $800 \mathrm{H}$.

Figure 3 shows photographs of $316 \mathrm{NG}, 800 \mathrm{H}$ and 625 alloys after exposure for $500 \mathrm{~h}, 1000 \mathrm{~h}, 2000 \mathrm{~h}$ and $3000 \mathrm{~h}$. In case of evolution of their surface colorations, a significant difference was observed. After $500 \mathrm{~h}$ exposure, the surface of $316 \mathrm{NG}$ had a rusty red tint and finally became light blue; As for $800 \mathrm{H}$, the color of its surface became from dark blue to grey; The color of alloy 625 changed from dark brown to dark blue, finally to grey. It has commonly been suggested that the evolution of a thicker oxide layer possibly of different stoichiometries and the carbon deposition on the surface result in the change in color during exposure [30,31]. In addition to the change of color, no obvious breakaway oxidation or cracking were observed for all of specimens.

\subsection{SEM surface morphology}

Figure 4 showed the surface morphology of $316 \mathrm{NG}, 800 \mathrm{H}$ and 625 alloys after $3000 \mathrm{~h}$ exposure and the corresponding EDS quantification were listed in Table 2. Except for $800 \mathrm{H}$, there was no obvious change in the surface morphology up to $3000 \mathrm{~h}$ exposure and the initial grounding traces were visible for both $316 \mathrm{NG}$ and alloy 625 . Some dark spots randomly distributed on the surface of $800 \mathrm{H}$. The EDS compositional analysis (shown in Table 2) indicated that these dark spots were as a result of carbon deposition from $\mathrm{CO}_{2}$ containing atmosphere. Moreover, in higher magnification, corrosion products occurred at local defect position for $316 \mathrm{NG}$ and $800 \mathrm{H}$. EDS analysis result indicated carbon deposited on all the surfaces of three specimens, with at least $4.28 \mathrm{wt}$.\%. It is also worth noting that the true 
composition of oxides may not agree with that determined by EDS, which was due that the EDS detector picked up signal from beneath the a few microns of the specimen surface.

Table 2

Elemental compositions of different position in Fig. 4 (all in wt.\%).

\begin{tabular}{|lllllllllll|}
\hline Position & $\mathbf{C r}$ & $\mathbf{N i}$ & $\mathrm{Mn}$ & $\mathrm{Si}$ & $\mathbf{C}$ & $\mathrm{Fe}$ & $\mathbf{0}$ & $\mathrm{Mo}$ & $\mathrm{Al}$ & $\mathrm{Ti}$ \\
\hline Point 1 & 13.48 & 7.86 & - & 0.66 & 9.17 & 53.58 & 12.19 & 3.06 & - & - \\
\hline Point 2 & 15.17 & 9.58 & 1.34 & - & 8.15 & 54.54 & 7.87 & 2.86 & - & - \\
\hline Point 3 & - & 8.39 & - & - & 60.44 & 16.34 & 5.24 & - & - & - \\
\hline Point 4 & 18.39 & 25.85 & - & 1.84 & 4.28 & 40.07 & 8.76 & - & 0.52 & 0.30 \\
\hline Point 5 & 14.08 & 50.37 & - & 0.08 & 10.53 & 1.72 & 13.76 & 9.21 & 0.25 & - \\
\hline
\end{tabular}

\subsection{XRD and Raman analysis}

Figure 5 reveals XRD pattern of $316 \mathrm{NG}, 800 \mathrm{H}$ and 625 alloys after $3000 \mathrm{~h}$ exposure. Except for the diffraction peaks related with $\mathrm{y}-\mathrm{Fe}$, no obvious diffraction peak was found in Fig. 5. This result indicated the formed oxide layer was so thin that the composition and structure could not obtained through XRD measurement, even with low incident angle diffraction. Furthermore, Raman measurement was respectively preformed after $1000 \mathrm{~h}$ and $3000 \mathrm{~h}$ exposure, and the obtained results are shown in Fig. 6 . As shown in Raman spectra, a weak peak was detected after $1000 \mathrm{~h}$ exposure, corresponding to $\mathrm{Cr}_{2} \mathrm{O}_{3}$. The main peaks at 1340 and $1599 \mathrm{~cm}^{-1}$ were also due to the carbon deposition on the surface $[3,4,15]$. The above results all confirmed a fact that the continuous oxide film didn't form yet after $1000 \mathrm{~h}$ exposure in $500{ }^{\circ} \mathrm{C}$ and $20 \mathrm{MPa} \mathrm{SCO} 2$ environment. Continue to prolong exposure time to $3000 \mathrm{~h}$, the oxide films of $800 \mathrm{H}$ and alloy 625 were consisted by $\mathrm{Cr}_{2} \mathrm{O}_{3}$ (Raman shift marked with blue). For 316NG, Raman peaks correlated with $\mathrm{Fe}_{2} \mathrm{O}_{3}$ were detected as well, which may due to highest Fe content ( 67 wt.\%) compared with the other two.

\subsection{GDOES analysis}

Elemental distribution of cross section of the oxide layer after $1000 \mathrm{~h}$ exposure was analyzed using GDOES and the obtained result is shown in Fig. 7. For all of the specimens, a Cr-depletion zone formed at the interface between the oxide layer and the substrate, which was due to outward diffusion of $\mathrm{Cr}$ from the substrate and formation of Cr-rich oxide on gas/solid interface. Besides, Mn, Si for 316NG, Mn, Si for $800 \mathrm{H}$ and $\mathrm{Al}$, Ti for alloy 625 enriched at the respective substrate/oxide interface. Researchers suggested $\mathrm{Mn}$ from the underlying substrate was partially consumed to form the $(\mathrm{Cr}, \mathrm{Mn})_{3} \mathrm{O}_{4} \mathrm{Or} \mathrm{Mn}_{1.5} \mathrm{Cr}_{1.5} \mathrm{O}_{4}$ spinel oxides near the substrate/oxide interface $[7,11]$. A very thin and amorphous Si-rich oxide layer was also found in the interface in their study for 630 SS and 430 SS, which seemed to agree with ours. It was reported that internal silica layer could limit diffusing cations and anions, which was attributed that its structure could aid the formation of the external chromia layer [32]. In addition, as suggested by Lee [5] 
and Tan [33], $\mathrm{Al}_{2} \mathrm{O}_{3}$ and $\mathrm{TiO}_{2}$ could be formed at the interface between chromia layer and substrate as they were stable at much lower oxygen partial pressure. In case of carburization, enrichment of $C$ was not only in the air/solid interface, but also in underneath the oxide for $800 \mathrm{H}$. However, for $316 \mathrm{NG}$ and 625 alloys, enrichment of $\mathrm{C}$ was mainly on their surfaces. At last, the approximate thicknesses of the oxide layers after $1000 \mathrm{~h}$ exposure could also be obtained from GDOES results, and the values were about 40 $\mathrm{nm}, 45 \mathrm{~nm}$ and $25 \mathrm{~nm}$ respectively.

\subsection{TEM analysis}

In order to uncover the detailed microstructures and chemical composition at the substrate/oxide interface after $3000 \mathrm{~h}$ exposure, FIB lamellas containing the oxide layer was lifted out from $316 \mathrm{NG}, 800 \mathrm{H}$ and 625 specimens and TEM/EDS results are shown in Figs. 8-16. Figure 8 shows (a) STEM micrographs, (b)HAADF micrograph and (c) high-resolution STEM and corresponding Fast Fourier Transformation (FFT) micrographs of the cross section of 316NG. As shown in the STEM micrographs with lower and higher magnification, the oxide layer was continuous and compact, but its thickness was not uniform. According to the HAADF micrograph, its average thickness was in between $21 \mathrm{~nm}$ and 45 $\mathrm{nm}$. Compared with the thickness of the oxide after $1000 \mathrm{~h}$ exposure $(\sim 40 \mathrm{~nm})$, there was almost no change in thickness although another $2000 \mathrm{~h}$ exposure was performed. Figure 9 shows the results of EDS mapping near the interface between the oxide layer and the underlying substrate for $316 \mathrm{NG}$. It can be seen that, the whole oxide was Cr-rich oxide, and it was thought as $\mathrm{Cr}_{2} \mathrm{O}_{3}$ combined with XRD and Raman results. Moreover, $\mathrm{Mn}$ and Fe was accumulated at the interface, especially enrichment of Fe was very clear in Fig. 9. Further EDS line scanning (Fig. 10) conformed a multilayer structure of the oxide layer of 316NG after $3000 \mathrm{~h}$ exposure, i.e., the outer layer of the oxide was $\mathrm{C}$-rich, the middle layer was Fe-rich and the inner layer was Mn-rich. High-resolution STEM and its FFT micrographs (Fig. 8c) showed that the Ferich oxide existed in the form of $\mathrm{Fe}_{3} \mathrm{O}_{4}$ or $\mathrm{Fe}_{2} \mathrm{O}_{3}$ (see Fig. 6), and no Mn containing crystal structure was found according FFT pattern, probably indicating Mn-rich oxide was in the form of amorphous state. The existence of $\mathrm{C}$ in the oxide was due to carburization from $\mathrm{CO}_{2}$ containing atmosphere.

Figure 11 shows (a) STEM micrographs, (b)HAADF micrograph and (c) high-resolution STEM and corresponding Fast Fourier Transformation (FFT) micrographs of the cross section of $800 \mathrm{H}$. It could see clearly from STEM micrographs that the oxide layer was continuous, compact and its thickness was uniform, which was different from that of $316 \mathrm{NG}$. From HAADF micrograph, the thickness of the oxide was about $64 \sim 88 \mathrm{~nm}$ after $3000 \mathrm{~h}$ exposure. In contrast with the oxide after $1000 \mathrm{~h}(\sim 45 \mathrm{~nm})$, its thickness increased by $45 \% \sim 96 \%$ at different regions after operating another $2000 \mathrm{~h}$ exposure. Figure 12 shows the results of EDS mapping near the oxide/substrate interface for $800 \mathrm{H}$. In addition to enrichment $\mathrm{Mn}$ and $\mathrm{Fe}$, Al was also found to enrich at the oxide/substrate interface. Unusually, it was commonly suggested that $\mathrm{Al}$ existed in form of $\mathrm{Al}_{2} \mathrm{O}_{3}$ with either crystal state or amorphous state [5]. The $\mathrm{Al}_{2} \mathrm{O}_{3}$ scales have proven to be particularly protective in containing carbon- or sulfur-species and water vapor aggressive atmosphere [23]. Especially, its carburization resistance was even superior to that of $\mathrm{Cr}_{2} \mathrm{O}_{3}[9$, 23]. However, as suggested Lee [23], the presence of Al-rich surface layer alone is not enough to provide 
sufficient corrosion and carburization resistance, unless pre-oxidation above $900^{\circ} \mathrm{C}$ was applied to form a more protectivea- $\mathrm{Al}_{2} \mathrm{O}_{3}$ on the surface. In our study, a relatively serious carburization still occurred for $800 \mathrm{H}$ observed in Fig. 7 although the Al-rich oxides formed at the oxide/substrate interface. The reason could be attributed that: i) the Al-rich oxide layer was not continuous (marked with red arrow in EDS mapping of Al of Fig. 12) and ii) the temperature used was too low to form protectivea- $\mathrm{Al}_{2} \mathrm{O}_{3}$. As shown in Fig. 11c, only $\mathrm{Ni}_{6} \mathrm{MnO}_{8}$ crystal phase was found according to FFT pattern except for $\mathrm{Cr}_{2} \mathrm{O}_{3}$ phase, and no Al-containing crystal structure seemed to demonstrate this speculation. EDS line scanning of $800 \mathrm{H}$ is shown in Fig. 13. The Ni-rich matrix can be found not only on the surface of the oxide, but also at the oxide/substrate interface. Chen et al. [7] reported a similar phenomenon with ours, but Ni only precipitated at the oxide/substrate interface in their study. Due to the lower solubility of $\mathrm{Ni}$ in the oxides compared to that in the alloys, the oxides could serve as a diffusion barrier, resulting in the precipitate of $\mathrm{Ni}$ accumulated at the oxide/substrate interface. However, further experiment is necessary to prove how $\mathrm{Ni}$ diffuses to the surface of the oxide.

Figure 14 shows (a) STEM micrographs, (b) HAADF micrograph and (c) high-resolution STEM and corresponding Fast Fourier Transformation (FFT) micrographs of the cross section of alloy 625. The STEM micrographs indicated that the oxide layer was continuous, compact and its thickness was uniform as well. From HAADF micrograph, the thickness of the oxide layer was in between $31 \mathrm{~nm}$ and 43 $\mathrm{nm}$ after $3000 \mathrm{~h}$ exposure. Compared with the thickness of the oxide layer after $1000 \mathrm{~h}$ exposure $(\sim 25$ $\mathrm{nm}$ ), the thickness increased by $24 \% \sim 72 \%$ at different regions after operating another $2000 \mathrm{~h}$ exposure. Figure 15 shows the results of EDS mapping near the oxide/substrate interface for alloy 625 . Enrichment of $\mathrm{Ni}$, similar with that of $800 \mathrm{H}$, was also observed at the surface of the oxide, which was due to higher content of $\mathrm{Ni}$ in the alloy substrate (>30\%). From EDS line scanning (Fig. 16), except for Ni enrichment, $\mathrm{Ti}$ enriched inside of the oxide and $\mathrm{Al}$ enriched at the oxide/substrate interface. According to high-resolution STEM and its FFT pattern, only crystal structure of $\mathrm{Fe}_{3} \mathrm{O}_{4}$ was found except for $\mathrm{Cr}_{2} \mathrm{O}_{3}$, indicating Ti-rich and Al-rich oxides were in the form of amorphous state [27]. Moreover, there was no obvious carburization for alloy 625 , which agreed with GDOES and Raman results.

\subsection{Corrosion and carburization mechanism}

It is generally known that $\mathrm{Cr}$ has a higher diffusivity and a higher affinity for oxygen, resulting in priority formation of $\mathrm{Cr}_{2} \mathrm{O}_{3}$ scale on the surface of alloys. As the $\mathrm{Cr}_{2} \mathrm{O}_{3}$ scale grew, $\mathrm{Cr}$ removed from the alloy substrate causing a $\mathrm{Cr}$ depleted zone. From GDOES results after 1000 exposure, a $\mathrm{Cr}$ depleted zone was observed in all of the alloys. In case of $\mathrm{Ni}$, it had a lower oxygen affinity than $\mathrm{Fe}$, resulting that the diffusion rate into $\mathrm{Cr}_{2} \mathrm{O}_{3}$ scale for $\mathrm{Fe}$ higher than that for $\mathrm{Ni}$. Therefore, $\mathrm{Fe}$ oxide was found in the middle of the oxide in Figs. 9 and 12 (corresponding to 316NG and $800 \mathrm{H}$ ), and it didn't occur in alloy 625, which may be attributed to a lower Fe content ( 2.54 wt.\%). As for Si and Al, they tended to form beneath or at the substrate/oxide interface. It has been reported $\mathrm{Al}$ is a beneficial element to improve the carburization resistance of alloy. So far, a large number of studies have begun to focus depositing Al coating on the surface of alloys $[22,23,26]$. According to their results, the protective effect of the containing a-Al ${ }_{2} \mathrm{O}_{3}$ 
layer better than that of amorphous Al-rich layer alone. No enrichment of Si was observed in our TEM results, which may because the underlying silica oxide layer is slow to develop compared to alumina [32]. $\mathrm{Mn}$ and $\mathrm{Ti}$ are thought as detrimental to oxidation resistance. They could rapidly diffuse through the chromia scale and form oxide on the outer surface which thickens with time, increasing the overall oxidation rate [32].

As suggested by Lee et al. [5], the carburization can occur in unique $\mathrm{SCO}_{2}$ atmosphere by i) supplying $\mathrm{C}$ to the oxide/substrate interface through the oxide layer; ii) diffusing through the metal substrate and iii) forming carbides with metal elements. Although the solubility of $\mathrm{C}$ in the oxide is virtually zero, $\mathrm{CO}_{2}$ from environment can permeate through nano-channels, pores, cracks, or oxide grain boundaries. When $\mathrm{CO}_{2}$ reachesthe oxide/substrate interface, it will interact with $\mathrm{Cr}$ or $\mathrm{Fe}$ as the following reaction (1) [34]:

$x \mathrm{M}+y \mathrm{CO}_{2} \leftrightarrow \mathrm{M}_{x} \mathrm{O}_{y}+y \mathrm{CO}(1)$

Then $\mathrm{C}$ deposition occurs at the oxide/substrate interface through the Boudouard Reaction (2) during $\mathrm{SCO}_{2}$ exposure:

$2 \mathrm{CO} \leftrightarrow \mathrm{C}+\mathrm{CO}_{2}(2)$

By this way, C gradually accumulates at the oxide/substrate interface, and eventually develops into an amorphous $\mathrm{C}$ layer along with the growth of the oxide layer. Once the amorphous $\mathrm{C}$ layer is formed, it

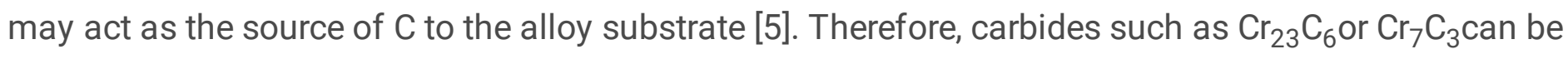
formed in the underlying substrate. In addition, at temperature greater than $425^{\circ} \mathrm{C}$ sensitization may occur in the austenitic stainless steel, causing the formation of $\mathrm{Cr}$ carbides at the grain boundary as well. It is worth noting that sensitization can also occur in nickel-based alloys, and ferritic stainless steels, but at higher temperatures [32]. Lee et al. [11] reported that ultimate tensile strength increased and elongation decreased after exposure in $\mathrm{SCO}_{2}$ for $800 \mathrm{HT}$. And they suggested that $\mathrm{Cr}$-rich $\mathrm{M}_{23} \mathrm{C}_{6}$ carbides in $800 \mathrm{HT}$ contributed to additional loss of ductility [5]. According to the results in our study, no obvious amorphous $\mathrm{C}$ layer and carbides formed for all tested alloys. As for 316NG and alloy $625 \mathrm{C}$ deposition only occurred at the surface of the oxide and inside of the oxide, while carburization was also found at oxide/substrate interface of $800 \mathrm{H}$. In Fig. 13, C enriched at the interface between Ni-rich matrix and the oxide, which may also indicate the oxide scale had a degree of carburization resistance. Moreover, in generally, the lower $\mathrm{Cr}$ activity in the Ni-based alloys and lower solubility of $\mathrm{Ni}$ in carbide contributes to the carburization resistance of Ni-based alloys [5].

\section{Conclusion}

Compatibility and long-term integrity of candidate structural materials, including austenitic stainless steel $316 \mathrm{NG}$, Fe-Ni based alloy $800 \mathrm{H}$ and Ni-based alloy 625, were tested in $\mathrm{SCO}_{2}$ environment with $500{ }^{\circ} \mathrm{C}$ and $20 \mathrm{MPa}$. And the oxide formed during $3000 \mathrm{~h}$ exposure was systematically investigated, including 
corrosion kinetics, morphology, composition and structure. Based on the above tests and analysis, the following conclusions were drawn:

(1) The corrosion kinetics approximately followed a parabolic law for $316 \mathrm{NG}$ and $800 \mathrm{H}$, but not for alloy 625. Meanwhile, the oxidation rate of alloy 625 with high $\mathrm{Cr}$ and Ni content was $1 \sim 2$ order of magnitude lower than that of $316 \mathrm{NG}$ and $800 \mathrm{H}$ at first $1000 \mathrm{~h}$ exposure.

(2) From SEM surface morphologies of $316 \mathrm{NG}$ and 625 alloy, there was no obvious change up to $3000 \mathrm{~h}$ exposure. However, for $800 \mathrm{H}$, some dark spots corresponding carbon deposition (with $60.44 \mathrm{wt} \% \mathrm{C}$ content) formed on its surface.

(3) The main composition of the oxide scale was $\mathrm{Cr}_{2} \mathrm{O}_{3}$ for all tested alloy, and therefore resulting in a $\mathrm{Cr}$ depletion zone formed at the oxide/substrate interface. After $3000 \mathrm{~h}$ exposure, the thicknesses of the oxide scale for 316NG, 800H and alloy 625 were $21 \sim 45 \mathrm{~nm}, 64 \sim 88 \mathrm{~nm}$ and $34 \sim 43 \mathrm{~nm}$ respectively. In contrast with $1000 \mathrm{~h}$ exposure, the increase in thickness was highest with $45 \% \sim 96 \%$ for $800 \mathrm{H}$.

(4) Enrichment of trace elements were observed at oxide/substrate interface, i.e., enrichment of Mn, Si for $316 \mathrm{NG}$, enrichment of $\mathrm{Mn}, \mathrm{Si}, \mathrm{Al}, \mathrm{Ti}$ for $800 \mathrm{H}$ and enrichment of $\mathrm{Ti}, \mathrm{Al}$ for alloy 625 . And they existed in theform of amorphous oxide state.

(5) In case of carburization, for $800 \mathrm{H}$, enrichment of $\mathrm{C}$ was not only in the air/solid interface, but also in underneath the oxide for $800 \mathrm{H}$. However, for $316 \mathrm{NG}$ and 625 alloys, enrichment of $\mathrm{C}$ was mainly on their surfaces.

\section{Declarations}

\section{Acknowledgements}

This work was supported by the National Key Research and Development Program of China (No. 2018YFE0116200).

\section{References}

1. Kim SH, Cha J-H, Jang C, Sah I, Microstructure and Tensile Properties of Diffusion Bonded Austenitic Fe-Base Alloys-Before and After Exposure to High Temperature Supercritical- $\mathrm{CO}_{2}$, Metals, 10 (2020) 480 .

2. Lee HJ, Kim SH, Jang C, Characterization of Alloy 600 joints exposed to a high-temperature supercritical-carbon dioxide environment, Materials Characterization, 138 (2018) 245-54.

3. Liang Z, Gui Y, Wang Y, Zhao Q, Corrosion performance of heat-resisting steels and alloys in supercritical carbon dioxide at $650^{\circ} \mathrm{C}$ and $15 \mathrm{MPa}$, Energy, $175(2019) 345-52$. 
4. Gui Y, Liang Z, Shao H, Zhao Q, Corrosion behavior and lifetime prediction of VM12, Sanicro 25 and Inconel 617 in supercritical carbon dioxide at $600^{\circ} \mathrm{C}$, Corrosion Science, 175 (2020) 108870.

5. Lee HJ, Kim H, Kim SH, Jang C, Corrosion and carburization behavior of chromia-forming heat resistant alloys in a high-temperature supercritical-carbon dioxide environment, Corrosion Science, 99 (2015) 227-39.

6. Zhang GA, Liu D, Li YZ, Guo XP, Corrosion behaviour of N80 carbon steel in formation water under dynamic supercritical $\mathrm{CO}_{2}$ condition, Corrosion Science, 120 (2017) 107-120.

7. Chen H, Kim SH, Kim C, Chen J, Jang C, Corrosion behaviors of four stainless steels with similar chromium content in supercritical carbon dioxide environment at $650^{\circ} \mathrm{C}$, Corrosion Science, 156 (2019)16-31.

8. Olivares RI, Young DJ, Nguyen TD, Marvig P, Resistance of High-Nickel, Heat-Resisting Alloys to Air and to Supercritical $\mathrm{CO}_{2}$ at High Temperatures, Oxidation of Metals, 90 (2018) 1-25.

9. He L-F, Roman P, Leng B, Sridharan K, Anderson M, Allen TR, Corrosion behavior of an alumina forming austenitic steel exposed to supercritical carbon dioxide, Corrosion Science, 82 (2014) 67-76.

10. Mahaffey J, Kalra A, Anderson M, Sridharan K. Materials corrosion in high temperature supercritical carbon dioxide, The 4th International Symposium - Supercritical $\mathrm{CO}_{2}$ Power Cycles. Pittsburgh, Pennsylvania, 2014. p. 1-8.

11. Lee HJ, Subramanian GO, Kim SH, Jang C, Effect of pressure on the corrosion and carburization behavior of chromia-forming heat-resistant alloys in high-temperature carbon dioxide environments, Corrosion Science, 111 (2016) 649-58.

12. Lee HJ, Kim H, Jang C. Compatibility of candidate structural materials in high-temperature $\mathrm{S}-\mathrm{CO}_{2}$ environment, The 4th International Symposium-Supercritical $\mathrm{CO}_{2}$ Power Cycles. Pittsburgh, Pennsylvania, 2014.

13. Gui Y, Liang ZY, Yu M, Zhao QX, Corrosion Behavior and Mechanism of Heat-Resistant Steel T91 in High-Temperature Carbon Dioxide Environment, Materials Science Forum, 944 (2019) 398-403.

14. Mahaffey J, Schroeder A, Adam D, Brittan A, Anderson M, Couet A, Sridharan K, Effects of CO and $\mathrm{O}_{2}$ Impurities on Supercritical $\mathrm{CO}_{2}$ Corrosion of Alloy 625, Metallurgical and Materials Transactions $A$, 49 (2018) 3703-3714.

15. Mahaffey J, Adam D, Brittan A, Anderson M, Sridharan K, Corrosion of Alloy Haynes 230 in High Temperature Supercritical Carbon Dioxide with Oxygen Impurity Additions. Oxidation of Metals, 86 (2016) 567-80.

16. Oleksak RP, Tylczak JH, Carney CS, Holcomb GR, Doğan ÖN, High-Temperature Oxidation of Commercial Alloys in Supercritical $\mathrm{CO}_{2}$ and Related Power Cycle Environments. Jom, 70 (2018)1527-34.

17. Wang HM, Shi SY, Fu XS, et al. Effect of Surface Nanocrystallization on Diffusion Bonding Process and Mechanical Property of Titanium Alloy and Titanium Aluminium Alloy at High Temperature, Journal of Netshape Forming Engineering, 12 (2020) 48-54. 
18. Chen $\mathrm{H}, \mathrm{Kim} \mathrm{SH}$, Jang C. Effect of high-temperature supercritical carbon dioxide exposure on the microstructure and tensile properties of diffusion-bonded Alloy 690, Journal of Materials Science, 55 (2019) 3652-3667.

19. Brittan A, Mahaffey J, Anderson M, The performance of Haynes 282 and its weld in supercritical $\mathrm{CO}_{2}$, Materials Science and Engineering: A, 759 (2019) 770-777.

20. Brittan AM, Mahaffey JT, Colgan NE, Elbakhshwan M, Anderson MH, Carburization resistance of cucoated stainless steel in supercritical carbon dioxide environments, Corrosion Science, 169 (2020) 108639.

21. Kim SH, Kim C, Cha J-H, Jang C, Corrosion Behavior of Si Diffusion Coating on an Austenitic Fe-Base Alloy in High Temperature Supercritical-Carbon Dioxide and Steam Environment. Coatings, 10 (2020) 493.

22. Kim C, Cha J-H, Kim SH, Jang C, Kim TK, Development of aluminide diffusion coatings on ODS ferritic-martensitic steel for corrosion resistance in high temperature super critical-carbon dioxide environment, Applied Surface Science, 509 (2020) 145387.

23. Lee HJ, Kim SH, Kim H, Jang C, Corrosion and carburization behavior of Al-rich surface layer on $\mathrm{Ni}$ base alloy in supercritical-carbon dioxide environment, Applied Surface Science, 388 (2016) 483490.

24. Kim C, Kim SH, Cha J-H, Jang C, Kim TK, Cr diffusion coating to improve the corrosion resistance of an ODS steel in super-critical carbon dioxide environment, Surface and Coatings Technology, 374 (2019) 666-73.

25. Su JY, Cai HN, Wei ZY, et al. Preparation of Wear-resistant and Antifriction Coating for Slipper, Journal of Netshape Forming Engineering, 12 (2020) 138-142.

26. Kim SH, Obulan Subramanian G, Kim C, Jang C, Park KM, Surface modification of austenitic stainless steel for corrosion resistance in high temperature supercritical-carbon dioxide environment, Surface and Coatings Technology, 349 (2018) 415-25.

27. Kim SH, Cha J-H, Jang C, Corrosion and creep behavior of a Ni-base alloy in supercritical-carbon dioxide environment at $650^{\circ} \mathrm{C}$, Corrosion Science, 174 (2020) 108843.

28. Sridharan K, Corrosion of Structural Materials for Advanced Supercritical Carbon-Dioxide Brayton Cycle. 2017. p. 1-170.

29. Shi XH, Lyu Z, Hu YR,et al. Numerical Simulation for Influence of Cold and Thermal Sources on FSW Residual Stress, Journal of Netshape Forming Engineering, 12 (2020) 55-60.

30. Firouzdor V, Sridharan K, Cao G, Anderson M, Allen TR, Corrosion of a stainless steel and nickelbased alloys in high temperature supercritical carbon dioxide environment, Corrosion Science, 69 (2013) 281-291.

31. Firouzdor V, Cao GP, Sridharan K, Anderson M, Allen TR, Corrosion resistance of PM2000 ODS steel in high temperature supercritical carbon dioxide, Materials and Corrosion, 66 (2015) 137-42. 
32. Dunlevy MW, An Exploration of the Effect of Temperature on Different Alloys in a Supercritical Carbon Dioxide Environment: University of Massachusetts Lowell; 2009.

33. Tan L, Anderson M, Taylor D, Allen TR, Corrosion of austenitic and ferritic-martensitic steels exposed to supercritical carbon dioxide, Corrosion Science, 53 (2011) 3273-3280.

34. Subramanian GO, Lee HJ, Kim SH, Jang C, Corrosion and Carburization Behaviour of Ni-xCr Binary Alloys in a High-Temperature Supercritical-Carbon Dioxide Environment, Oxidation of Metals, 89 (2017) 683-697.

\section{Figures}

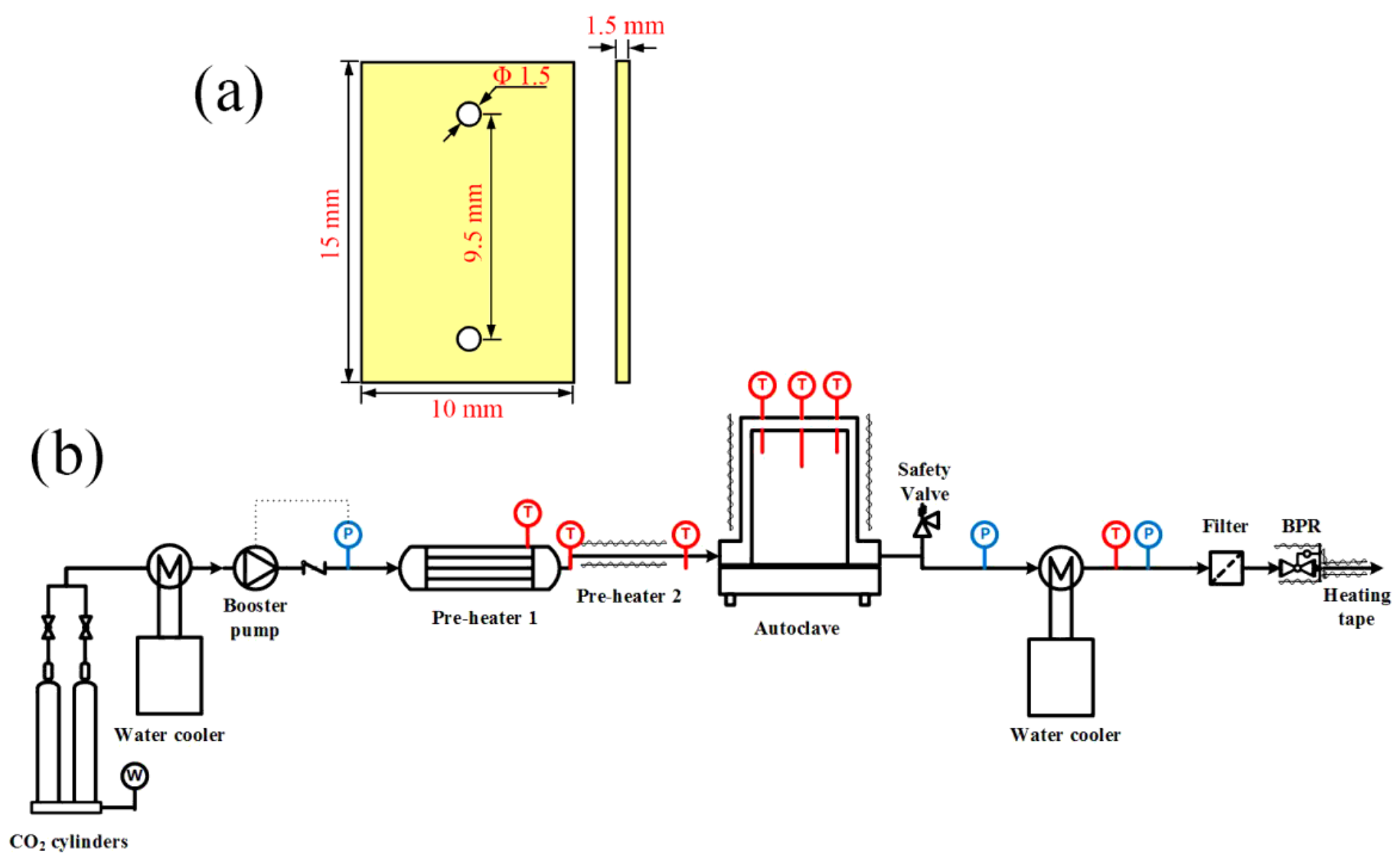

Figure 1

(a) Geometry and dimensions of coupon type specimens and (b) schematic of the $\mathrm{SCO}_{2}$ compatibility testing system. 

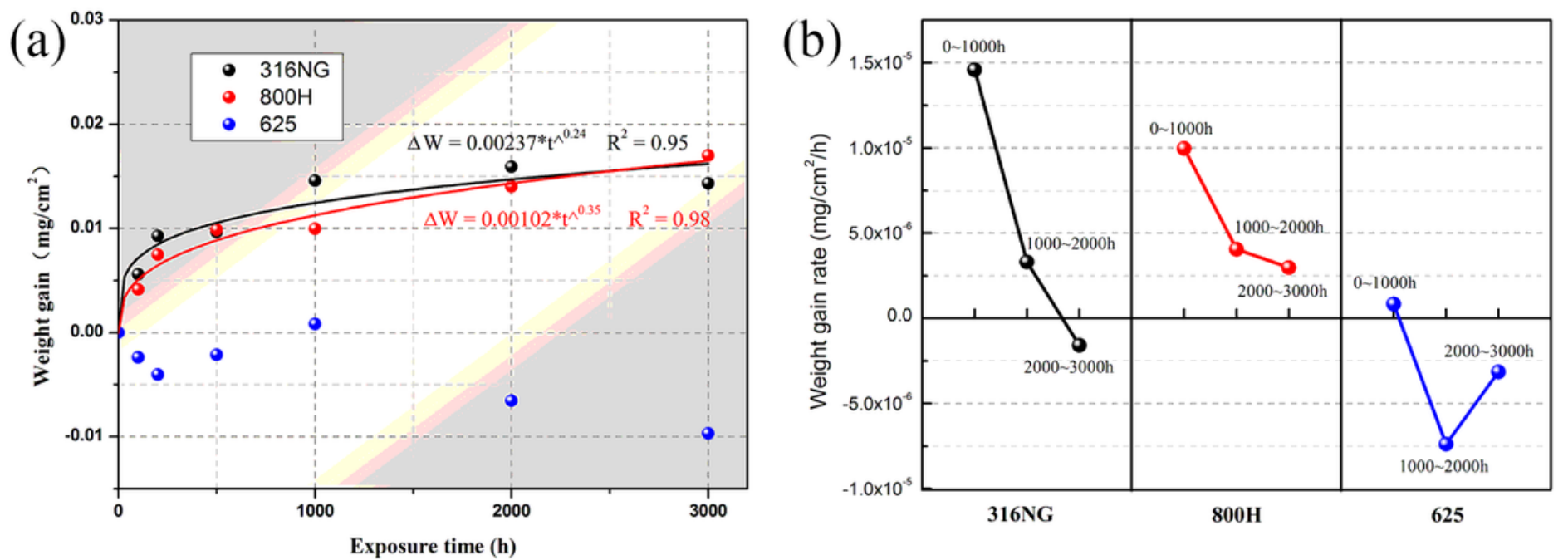

Figure 2

(a) Weight gains and (b) the oxidation rate during $3000 \mathrm{~h}$ exposure in $\mathrm{SCO}_{2}$ for $316 \mathrm{NG}, 800 \mathrm{H}$ and alloy 625. 


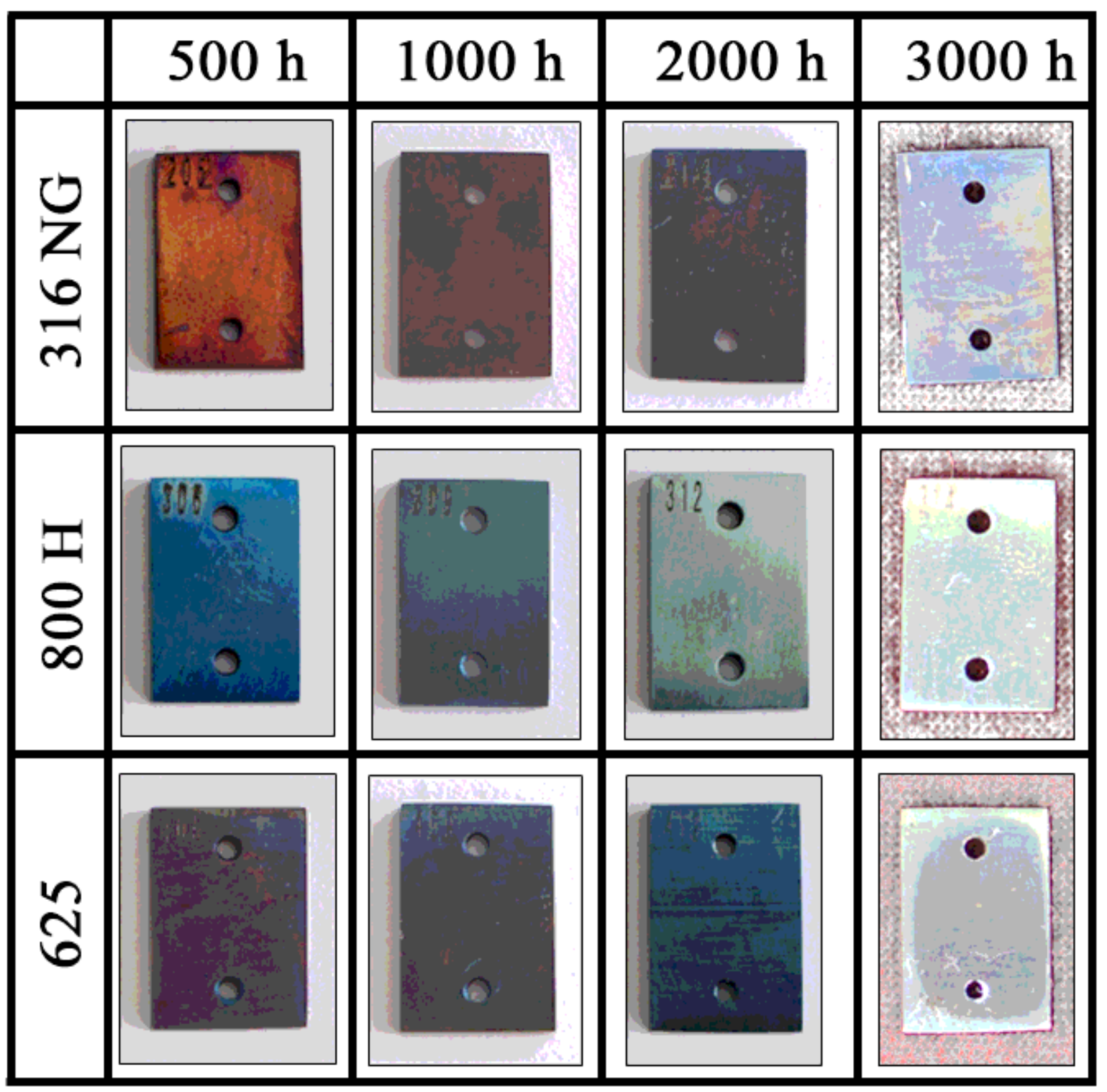

Figure 3

Photographs of $316 \mathrm{NG}, 800 \mathrm{H}$ and 625 alloys after exposure for $500 \mathrm{~h}, 1000 \mathrm{~h}, 2000 \mathrm{~h}$ and $3000 \mathrm{~h}$ in $\mathrm{SCO}_{2}$. 


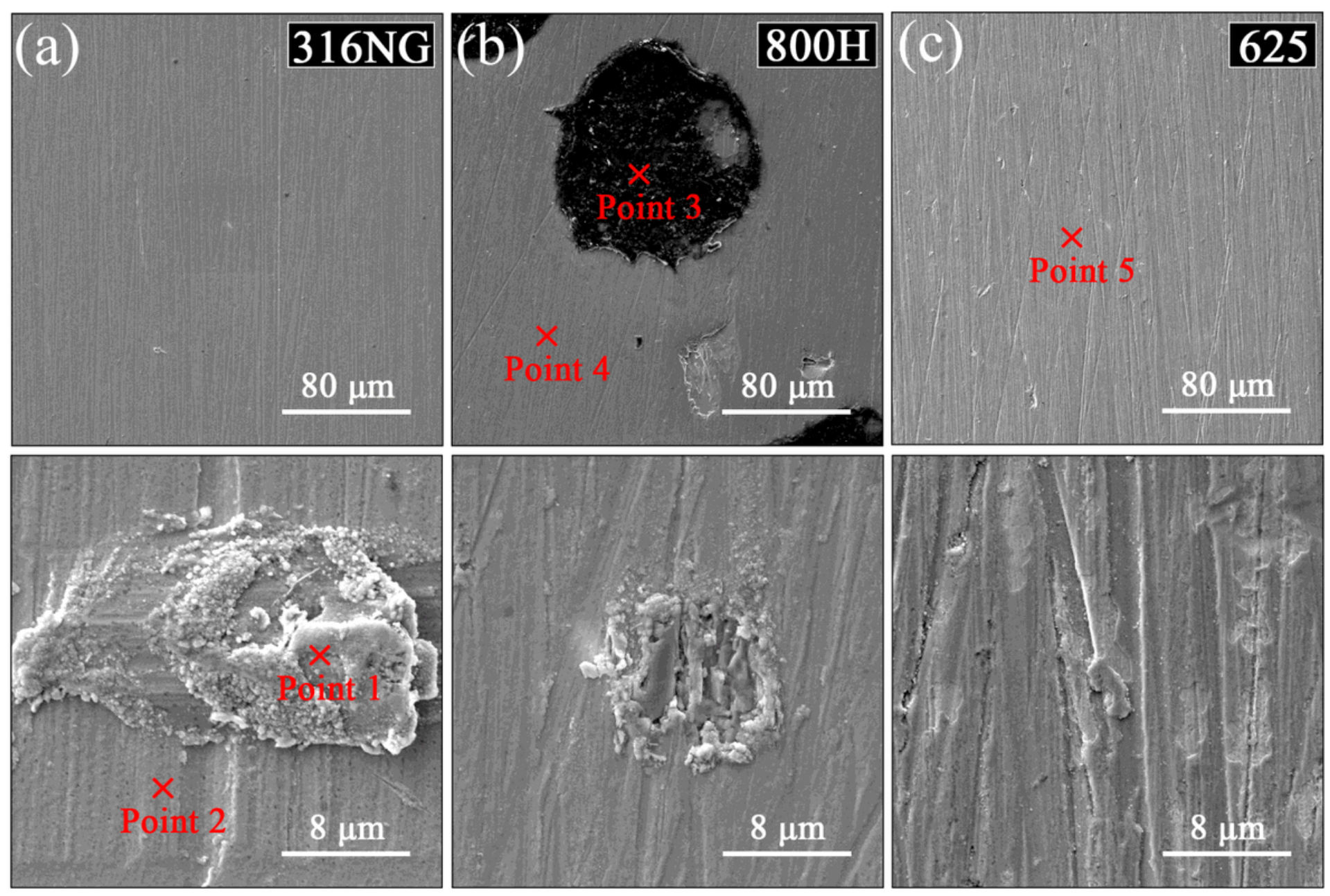

Figure 4

Surface morphologies of $316 \mathrm{NG}, 800 \mathrm{H}$ and 625 alloys after $3000 \mathrm{~h}$ exposure in $\mathrm{SCO}_{2}$. 


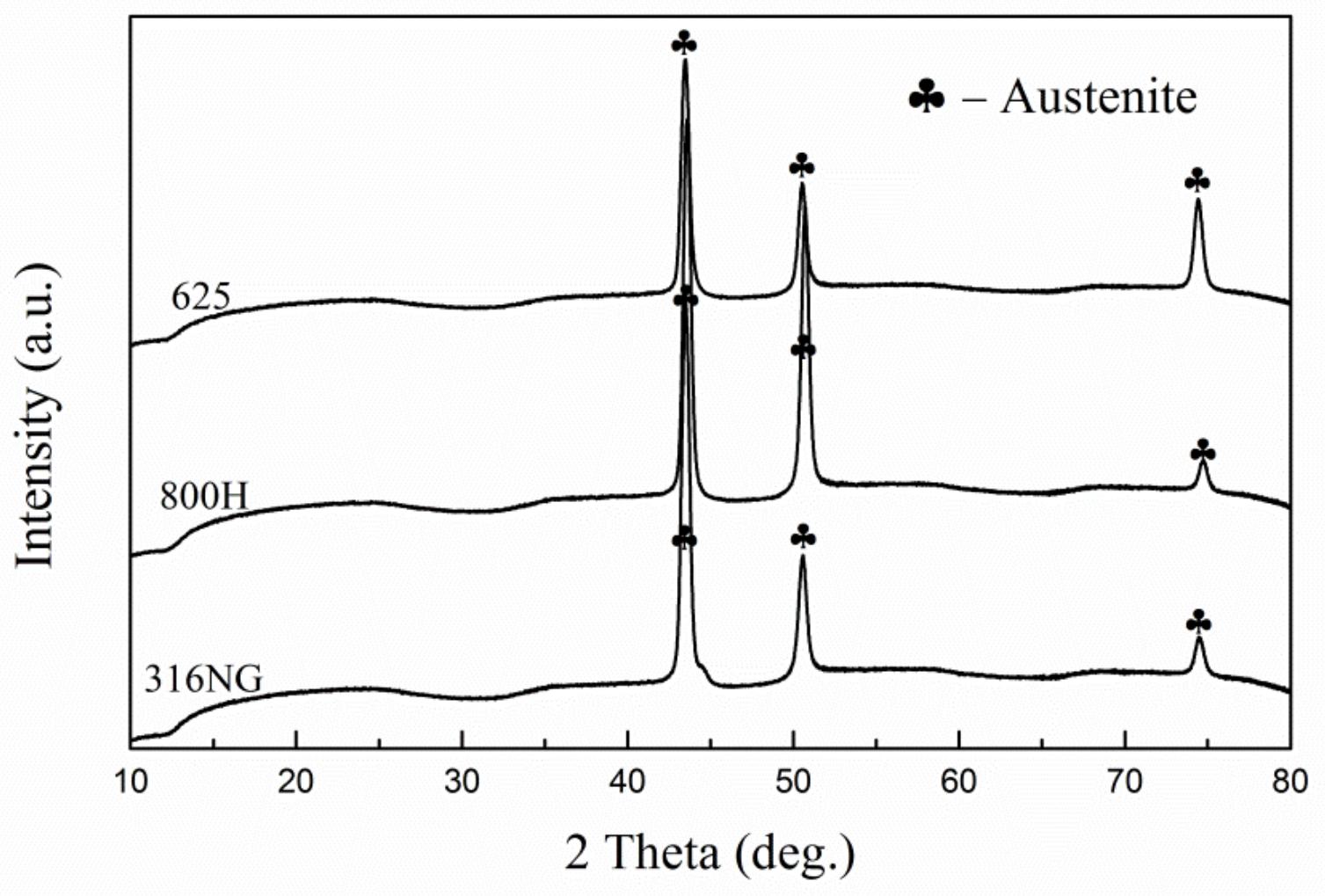

Figure 5

XRD pattern of $316 \mathrm{NG}, 800 \mathrm{H}$ and 625 alloys after $3000 \mathrm{~h}$ exposure in $\mathrm{SCO}_{2}$. 

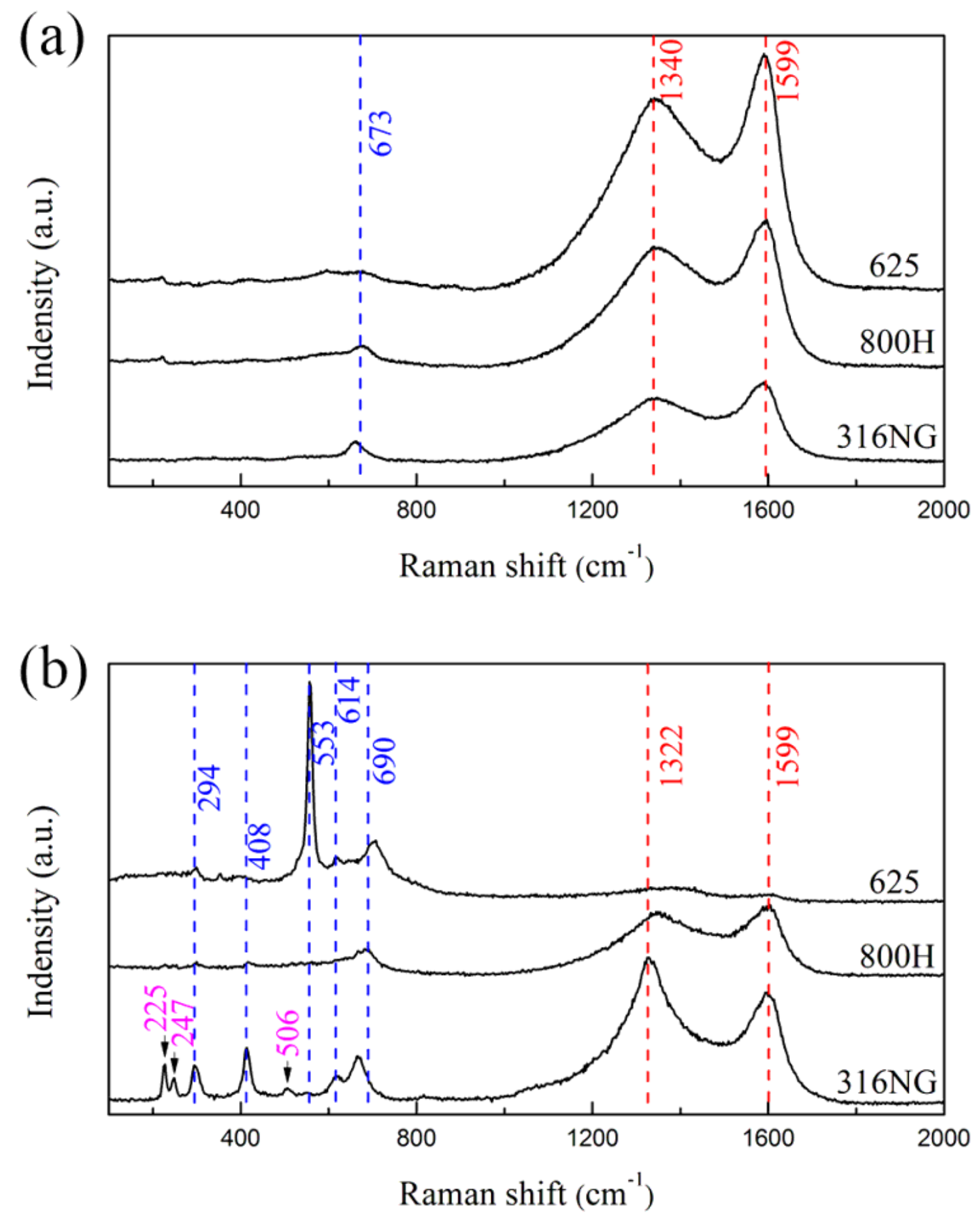

Figure 6

Raman results of $316 \mathrm{NG}, 800 \mathrm{H}$ and 625 alloys after (a) $1000 \mathrm{~h}$ and (b) $3000 \mathrm{~h}$ exposure in $\mathrm{SCO}_{2}$. 

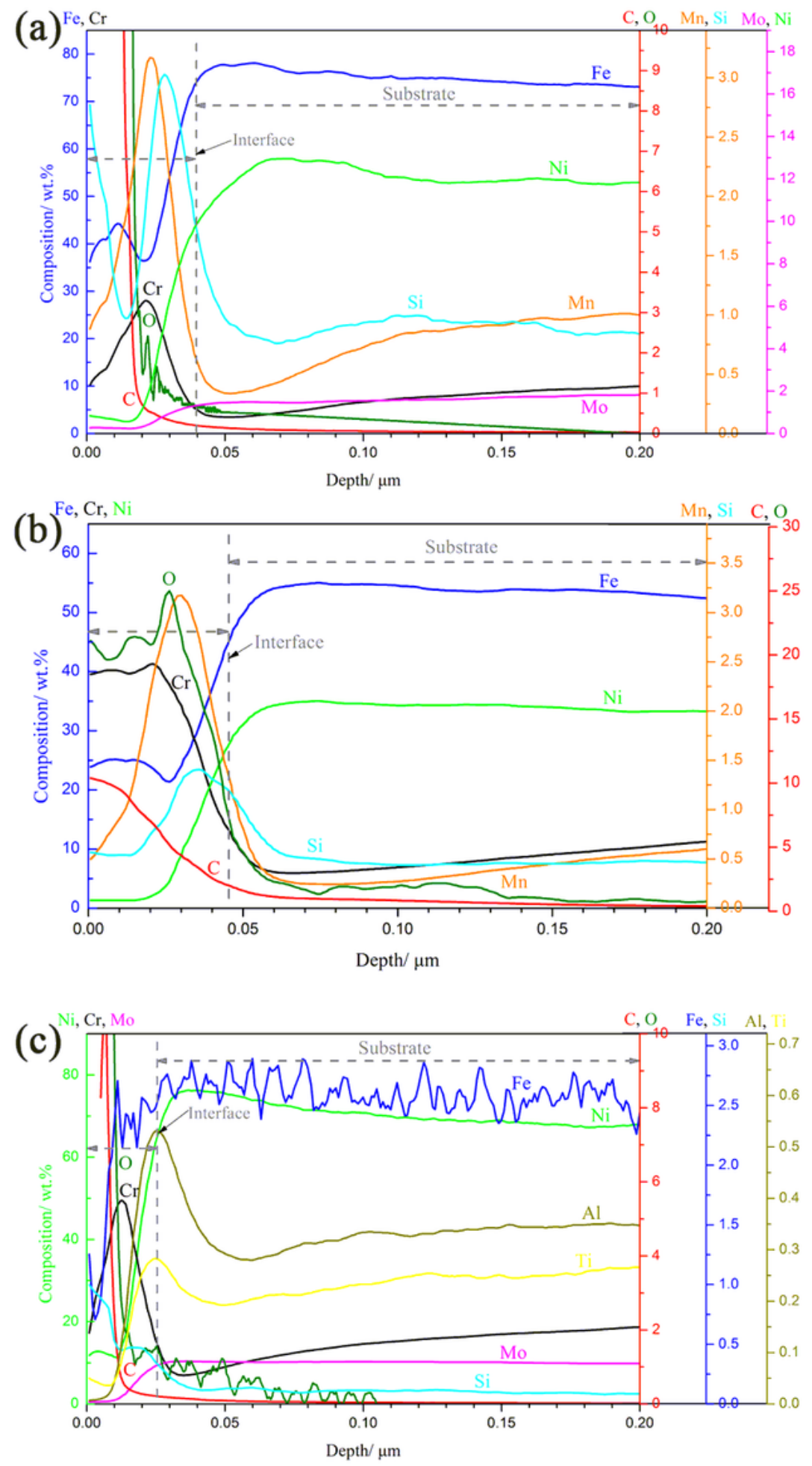

Figure 7

GDOES results of (a) $316 \mathrm{NG}$, (b) $800 \mathrm{H}$ and (c) 625 alloys after $1000 \mathrm{~h}$ exposure in $\mathrm{SCO}_{2}$. 


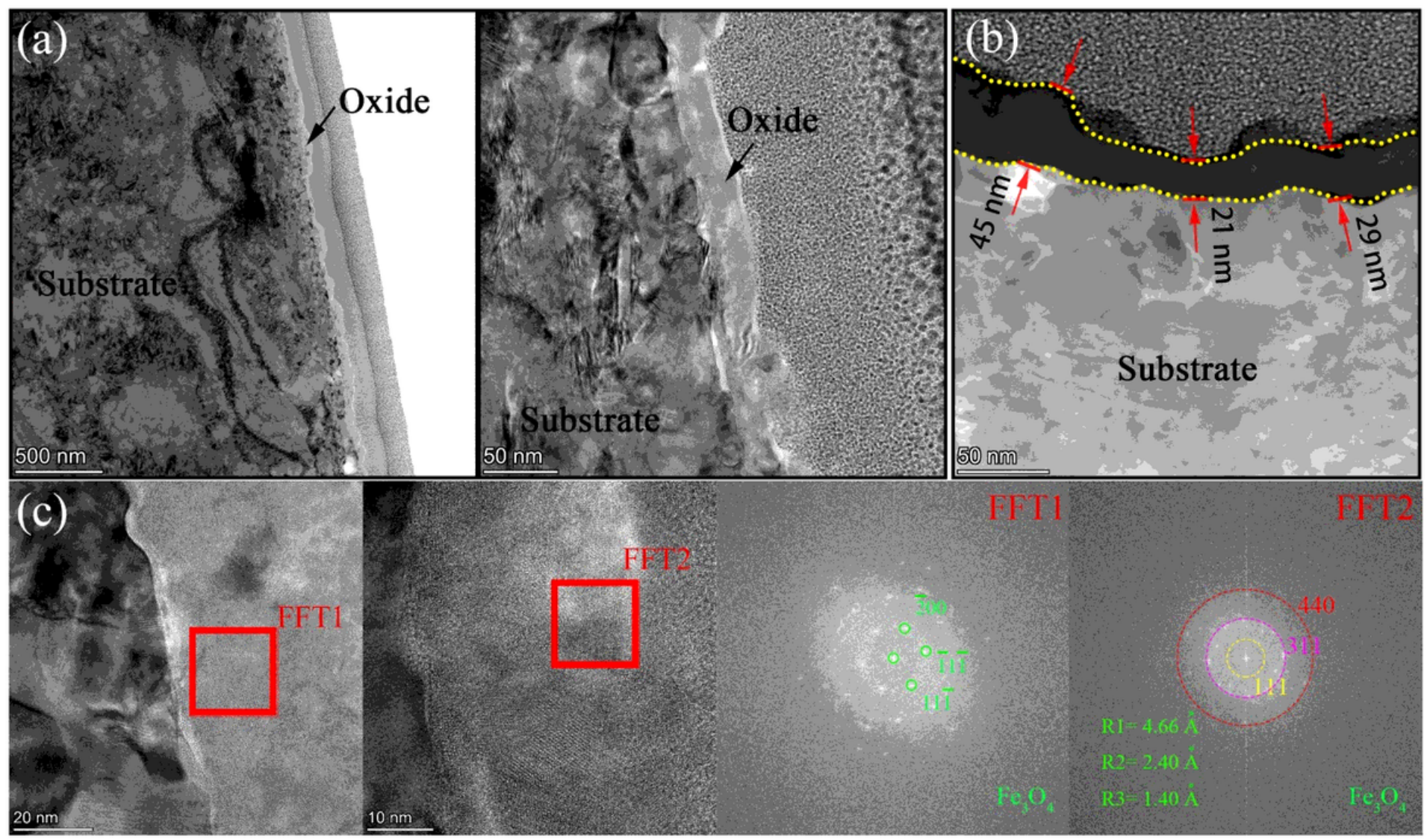

Figure 8

(a) STEM micrographs, (b)HAADF micrograph and (c) high-resolution STEM and corresponding Fast Fourier Transformation (FFT) micrographs of the cross section of 316NG. 


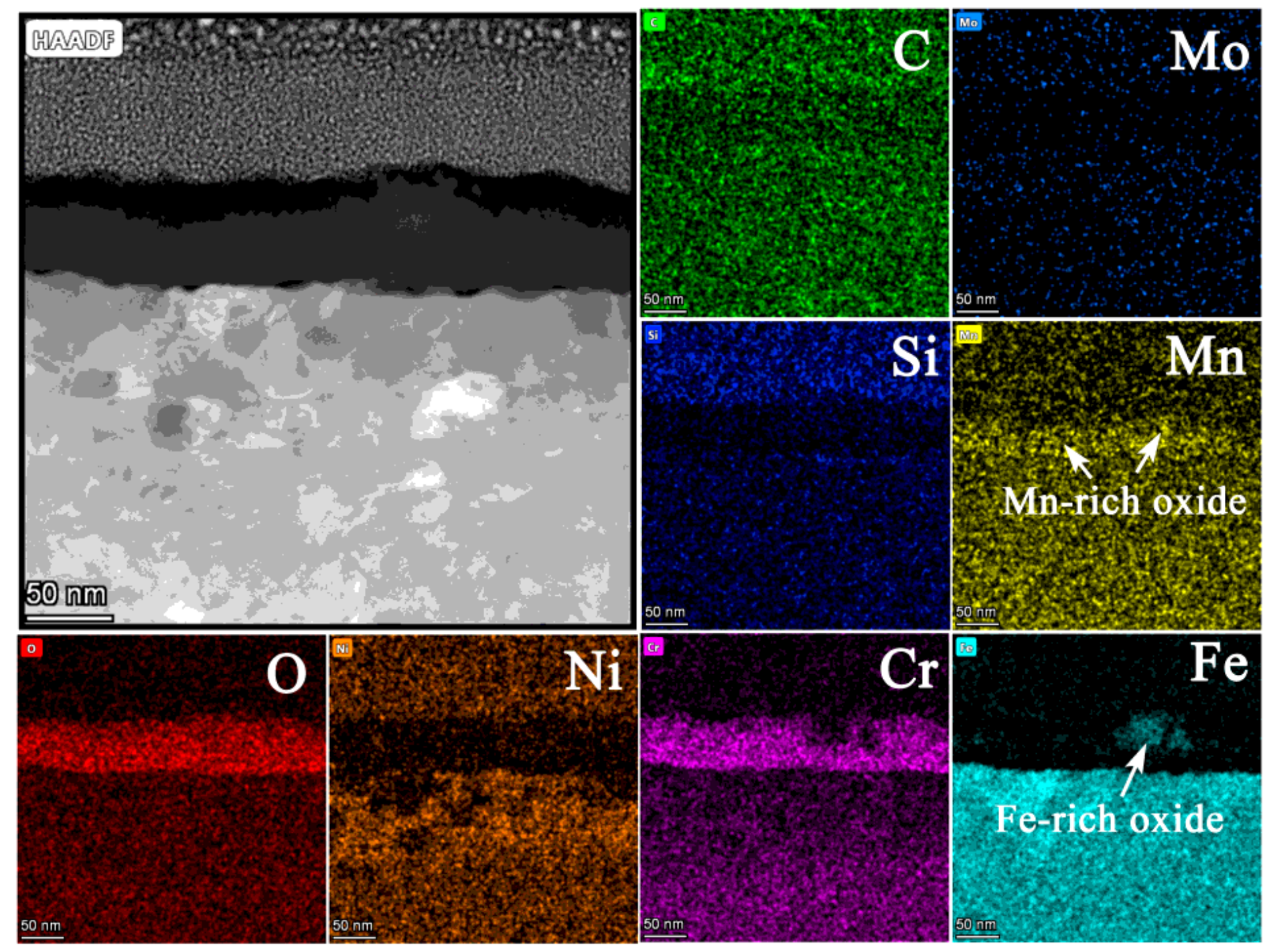

Figure 9

EDS mapping images of oxide layer of $316 \mathrm{NG}$ after $3000 \mathrm{~h}$ exposure in $\mathrm{SCO}_{2}$. 

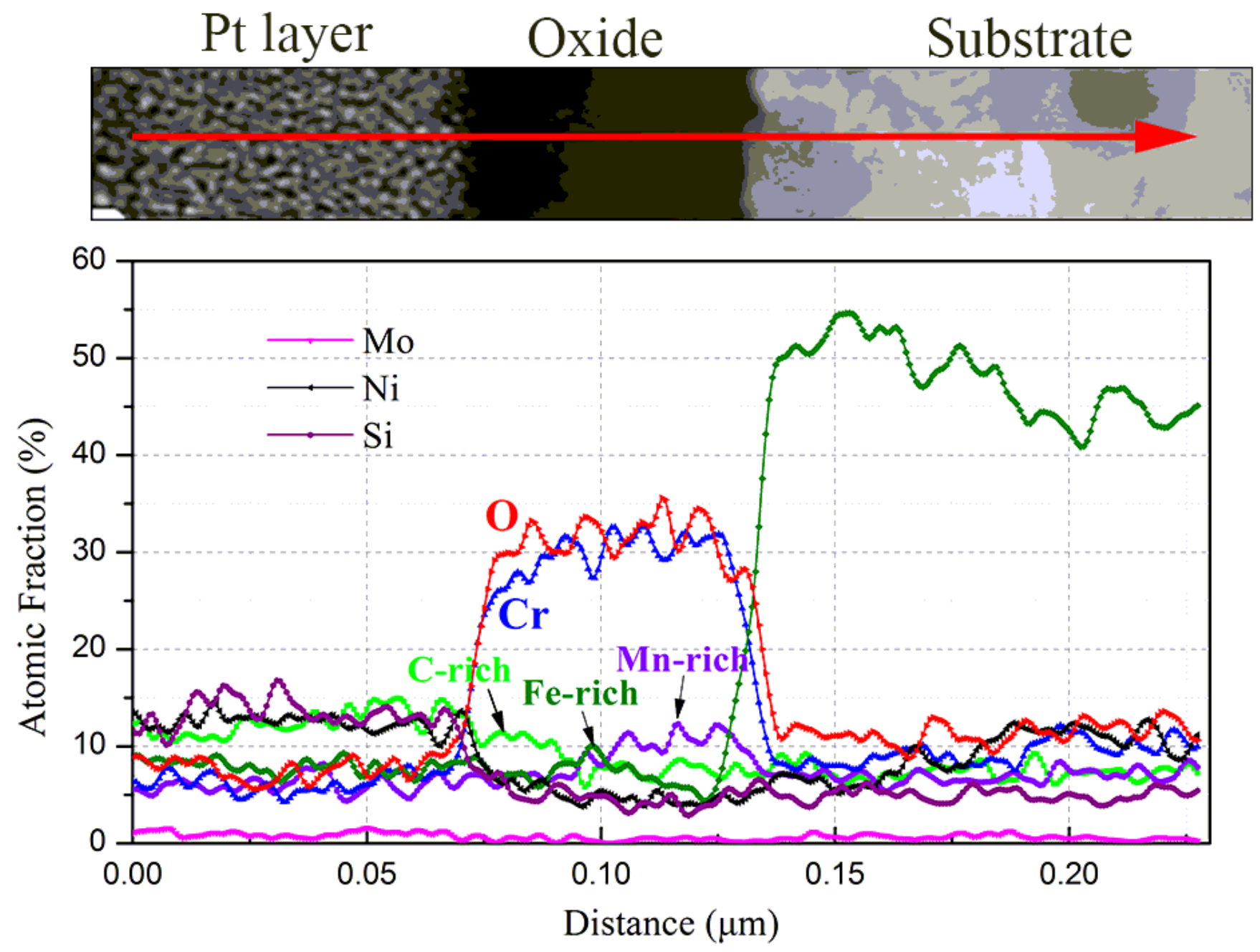

Figure 10

EDS line scanning of oxide layer of $316 \mathrm{NG}$ after $3000 \mathrm{~h}$ exposure in $\mathrm{SCO}_{2}$. 


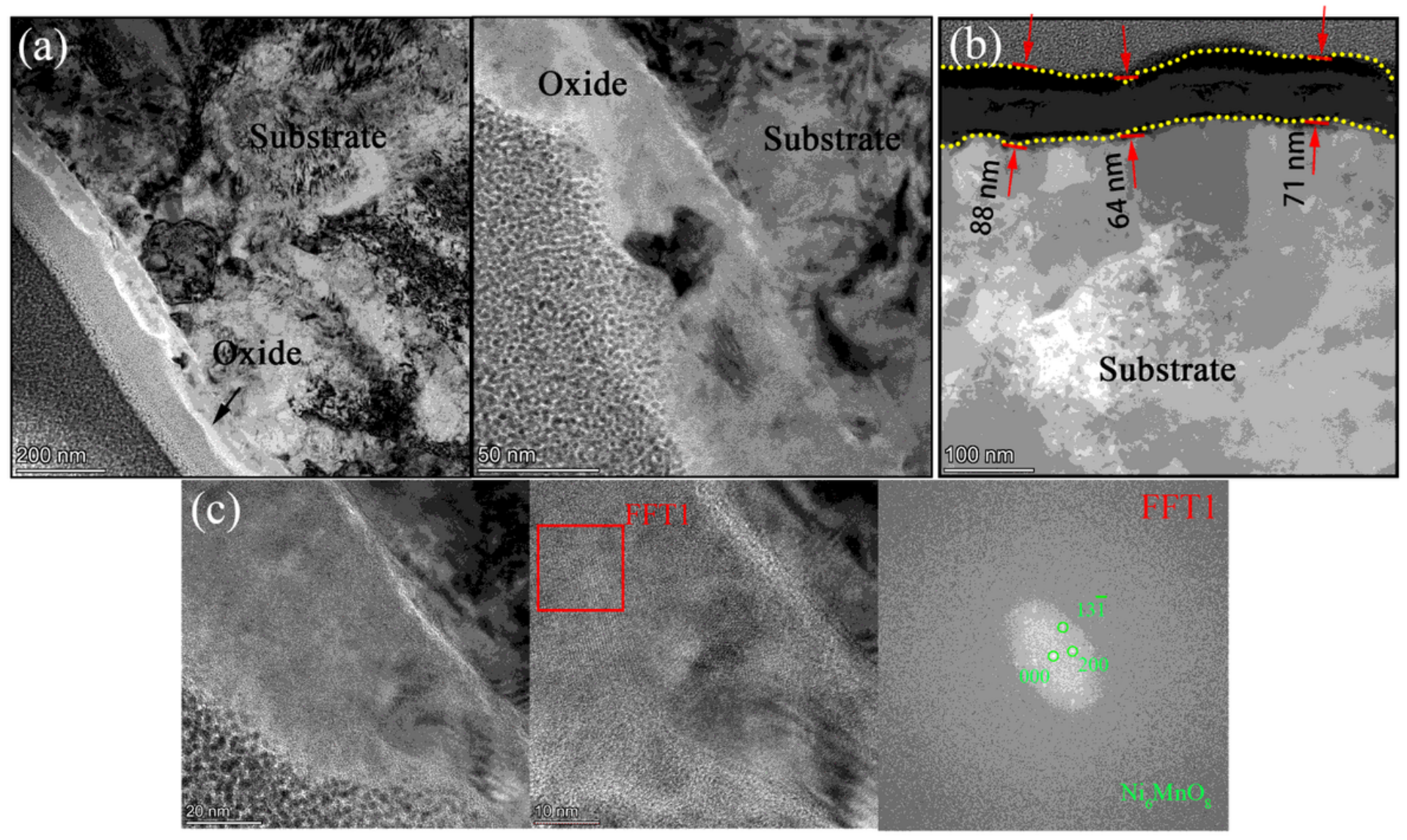

Figure 11

(a) STEM micrographs, (b)HAADF micrograph and (c) high-resolution STEM and corresponding Fast Fourier Transformation (FFT) micrographs of the cross section of $800 \mathrm{H}$. 


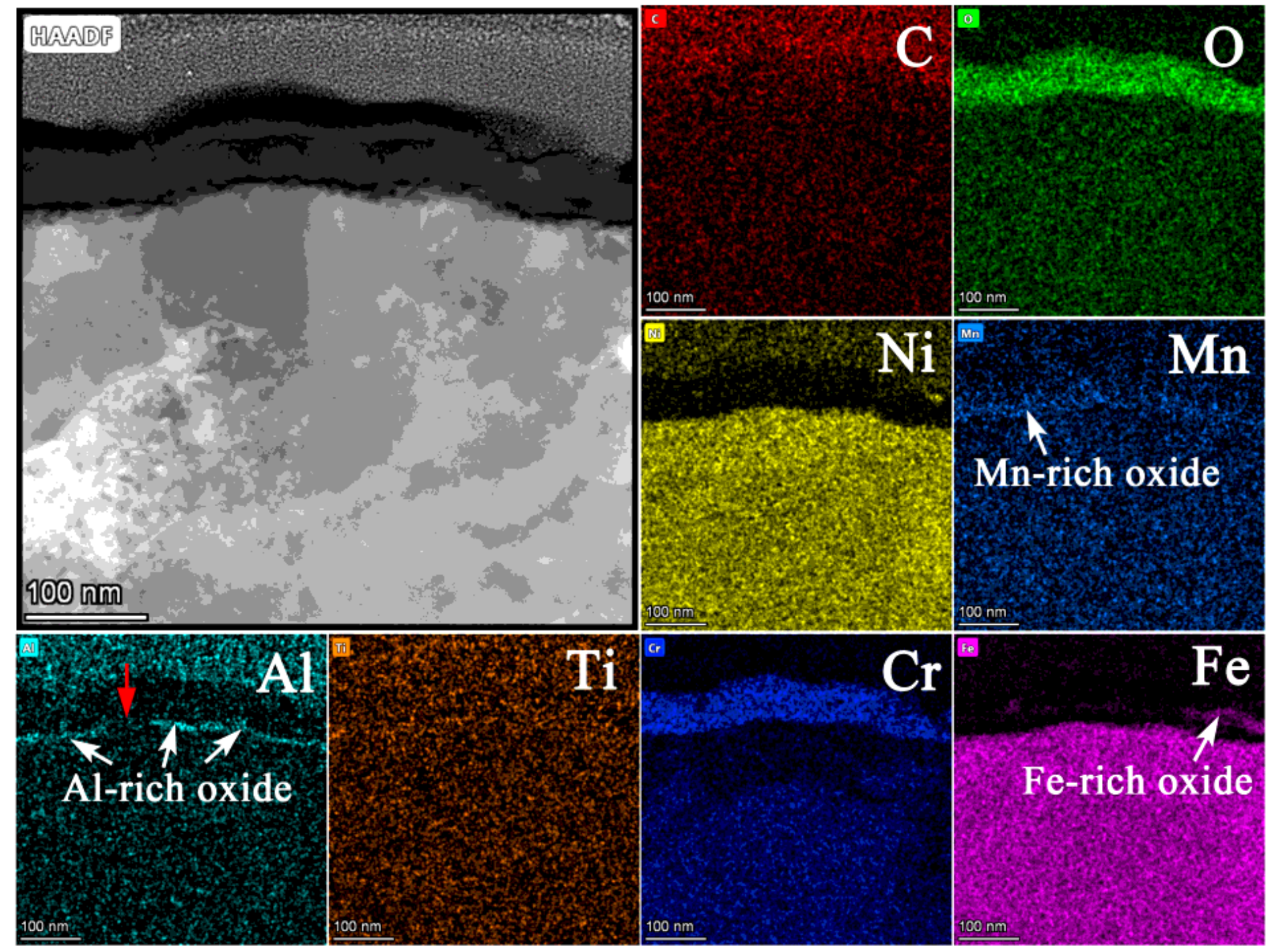

Figure 12

EDS mapping images of oxide layer of $800 \mathrm{H}$ after $3000 \mathrm{~h}$ exposure in $\mathrm{SCO}_{2}$. 

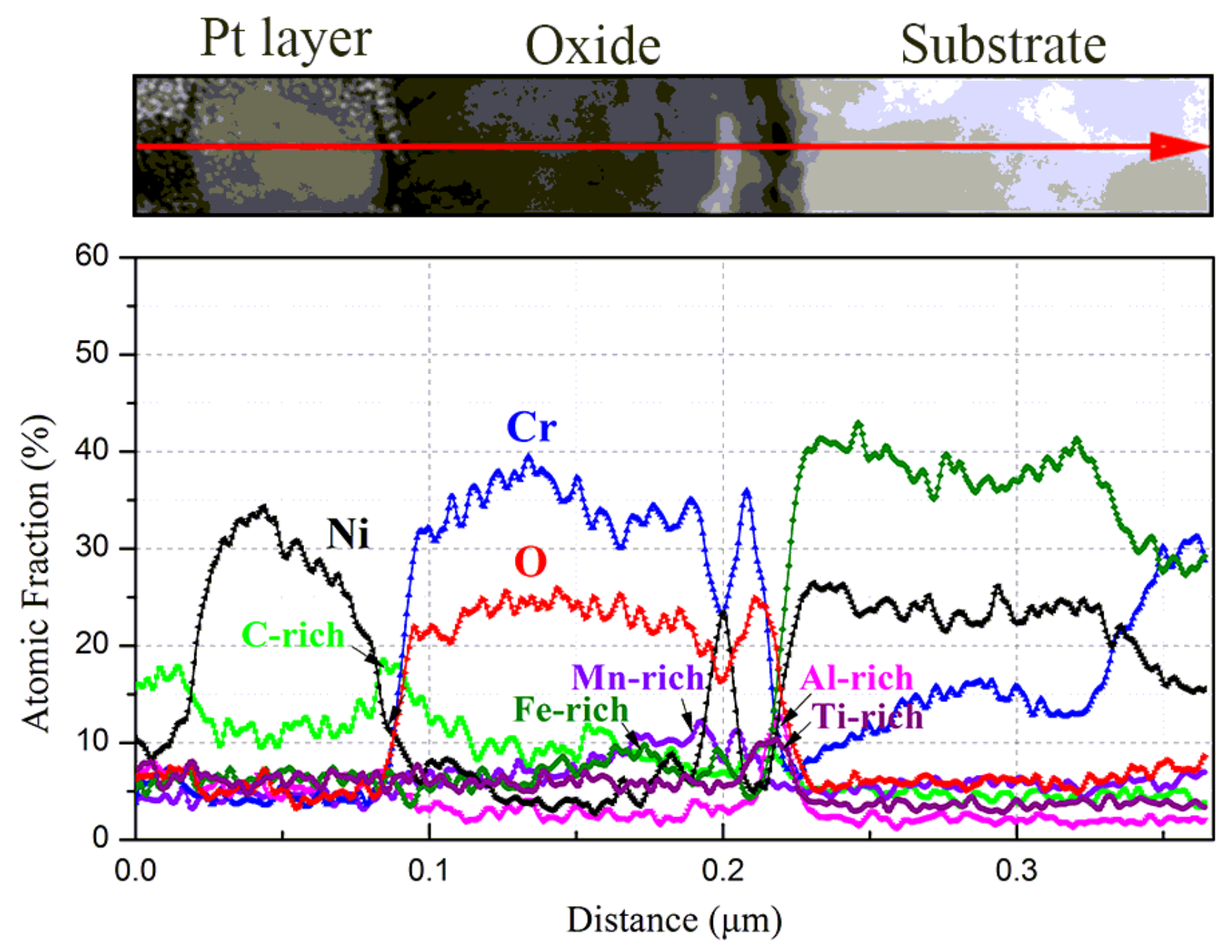

Figure 13

EDS line scanning of oxide layer of $800 \mathrm{H}$ after $3000 \mathrm{~h}$ exposure in $\mathrm{SCO}_{2}$. 


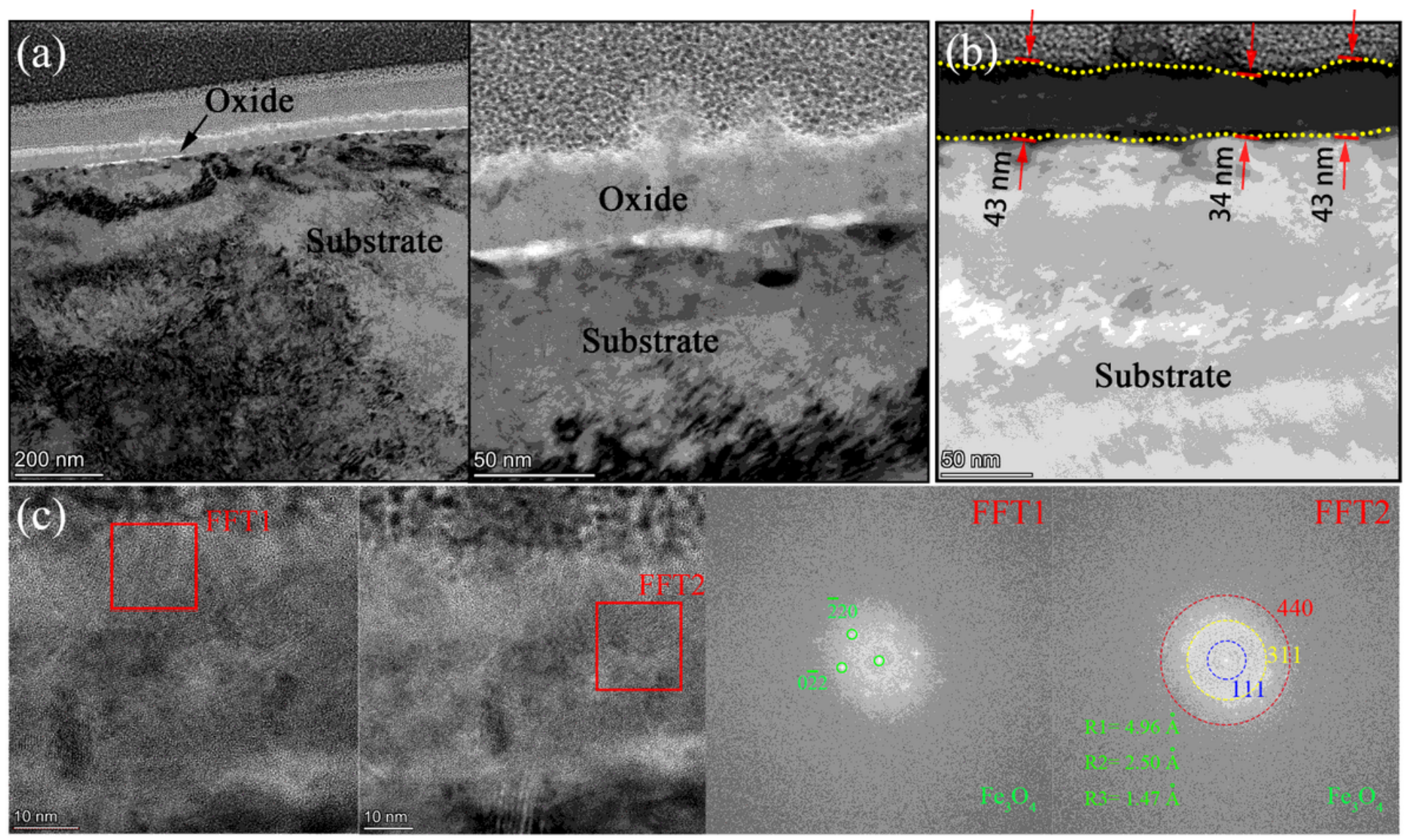

Figure 14

(a) STEM micrographs, (b) HAADF micrograph and (c) high-resolution STEM and corresponding Fast Fourier Transformation (FFT) micrographs of the cross section of alloy 625. 


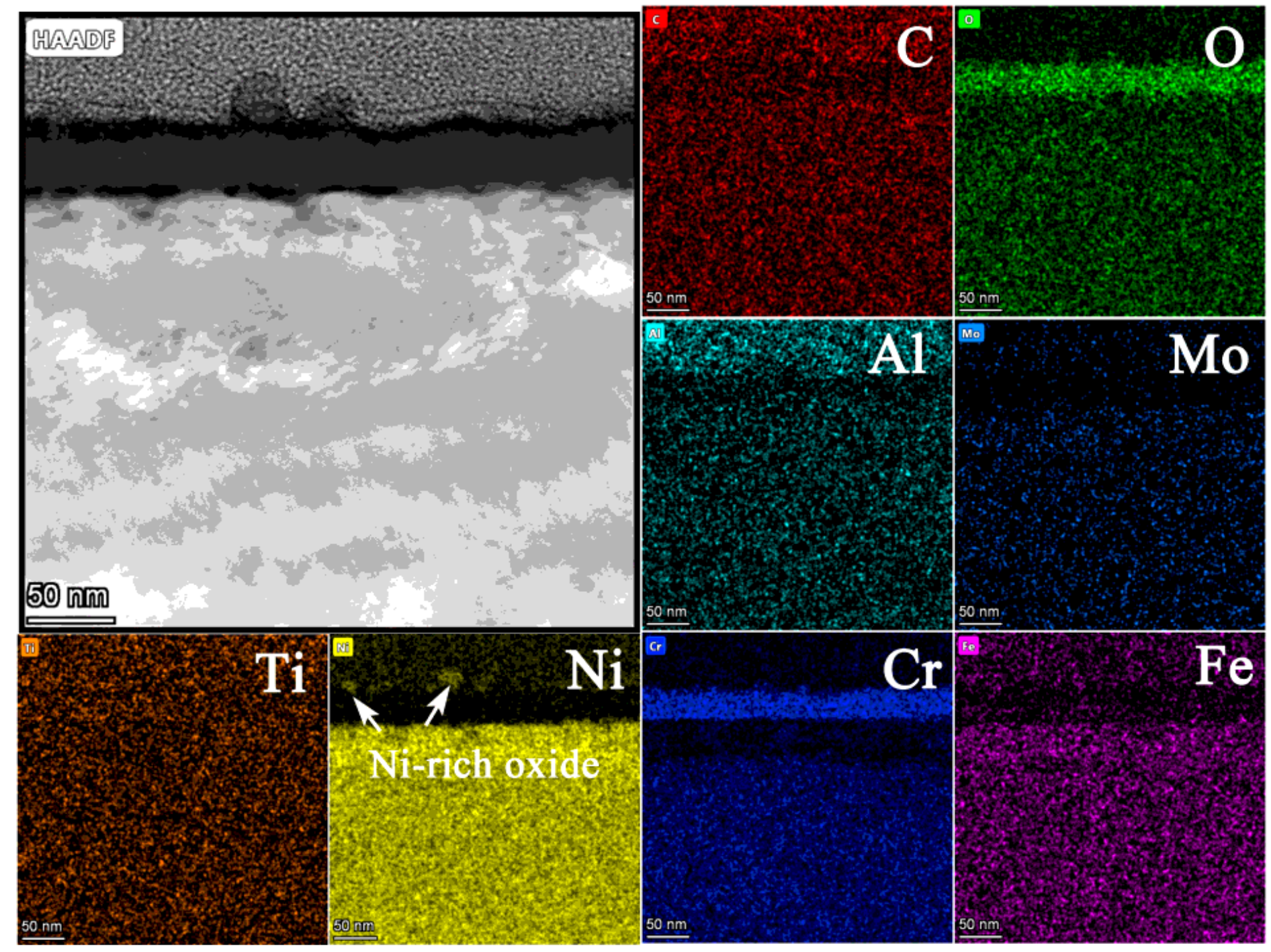

Figure 15

EDS mapping images of oxide layer of alloy 625 after $3000 \mathrm{~h}$ exposure in $\mathrm{SCO}_{2}$. 

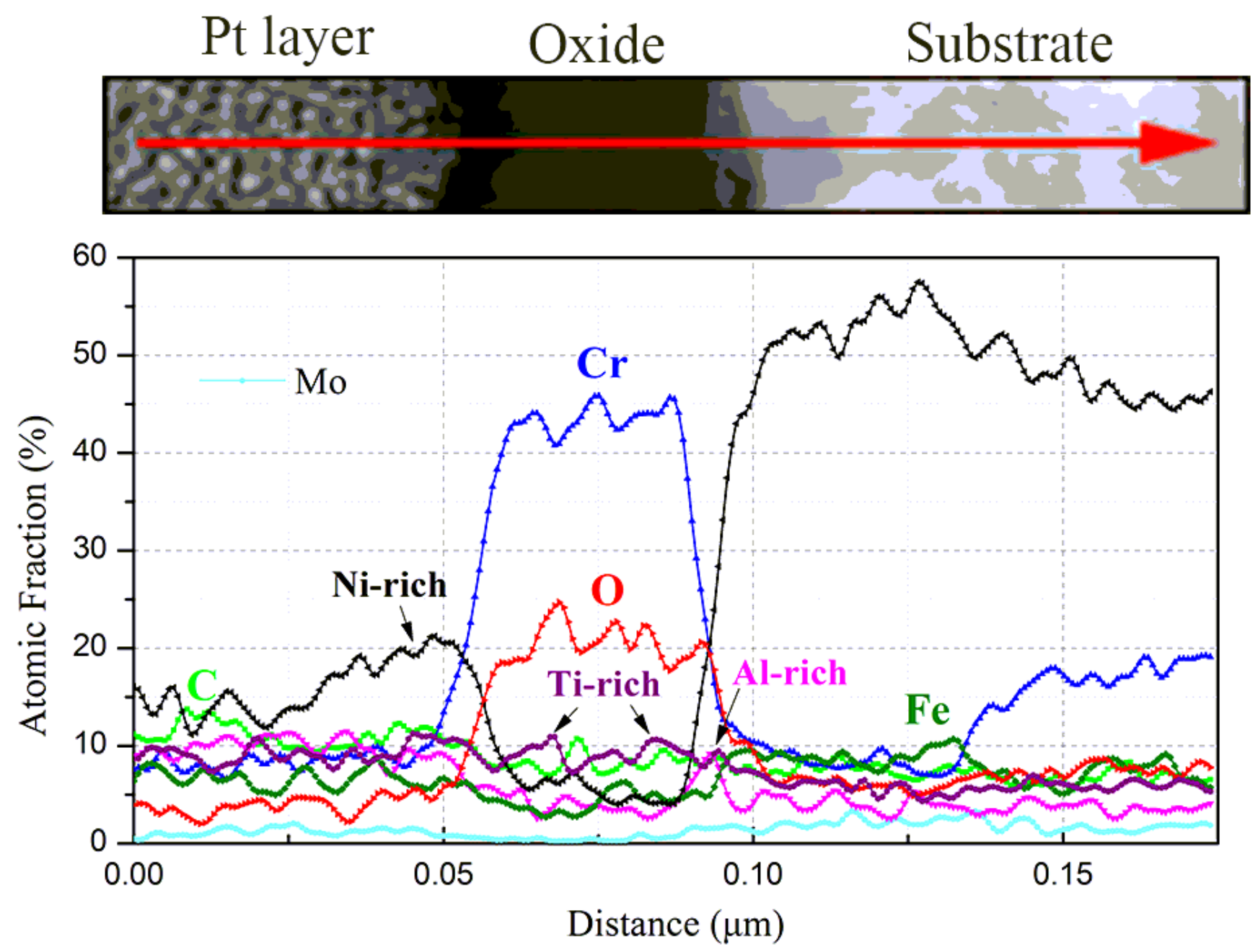

Figure 16

EDS line scanning of oxide layer of alloy 625 after $3000 \mathrm{~h}$ exposure in $\mathrm{SCO}_{2}$. 